\title{
Containment Amerika Serikat terhadap Fenomena Rise of China dalam Perspektif Hegemoni Realisme
}

\author{
Ary Arseno \\ Universitas Airlangga
}

\begin{abstract}
ABSTRAK
Paper ini menjelaskan strategi containment Amerika Serikat terhadap China, penulis berargumen bahwa Amerika Serikat menggunakan strategi untuk membendung fenomena kebangkitan China. Setelah Perang Dunia Kedua, China berkembang menjadi negara yang kuat dan mampu mengancam status hegemon tunggal Amerika Serikat. Containment sebagai strategi untuk membuat Washington tetap berada di puncak hirarki sistem internasional. Penulis membagi paper ini menjadi tiga bagian, pertama penulis menjelaskan tentang sistem relasi dan kerjasama yang Amerika Serikat bangun untuk membendung China. Pada bagian kedua, penulis menjelaskan tentang korelasi strategi containment dengan menggunakan teori ofensif realisme John Mearsheimer. Dan di bagian ketiga penulis menjelaskan kesimpulan dari paper ini.
\end{abstract}

Kata-Kata Kunci: Amerika Serikat, China, containment, realisme ofensif, John Mearsheimer

This paper explains about the United States' containment strategy toward China, the argue that the United States' strategy of containment aims to contain the China's rise phenomenon. After the Cold War, China has developed as a powerful country which has capability to threaten the United States' 'sole hegemon' status. Containment is the chosen strategy to keep Washington at the top of the hierarchy of international system. The author divide this paper into three sections, the first show the relations the United States builds to make containment works. Then in the section two, the author explain the United States' containment strategy with John Mearsheimer's offensive realism theory. The last section, I end this paper with conclusion that consists of important points of the paper.

Keywords: the United States, China, containment, offensive realism, John Mearsheimer 


\section{Pendahuluan}

Pasca Perang Dingin berakhir, runtuhnya Uni Soviet meninggalkan Amerika Serikat sebagai sole hegemon di muka bumi. Tidak adanya musuh secara ideologi juga membuat Amerika Serikat leluasa memperkenalkan ideologi liberalism ke seluruh dunia tanpa ada batasan teritori. Namun, keleluasaan Amerika Serikat dalam bergerak tidak berlangsung lama. Dibalik runtuhnya Uni Soviet dan berakhirnya Perang Dingin, satu kekuatan baru muncul dan kini dianggap mampu menyaingi Amerika Serikat sebagai negara hegemon yakni China rise. Fenomena yang dimulai sejak Perang dingin ditandai dengan keterbukaan China terhadap ekonomi hingga menjadikan China sebagai negara yang memiliki perekonomian besar saat ini. Hal ini yang nantinya membuat Amerika Serikat khawatir karena meningkatnya suatu perekonomian dapat memantik negara dalam meningkatkan kekuatan militernya. Sebagai mana menurut Mearsheimer (2010) bahwa kekuatan ekonomi dianggap tidak akan tumbuh dengan secara damai.

Dalam menghentikan China, menurut Mearsheimer (2006) menganjurkan bahwa Amerika Serikat harus tetap menjadi negara hegemon. Pasalnya jika terdapat suatu kekuatan yang mampu menyaingi Amerika sebagai negara hegemon, maka keamanan yang dimiliki Amerika akan terganggu sekalipun hal ini terjadi dalam lingkup regional hegemon (Mearsheimer, 2006). Berdasar hal tersebut, Amerika serikat menggunakan cara containment sebagai salah satu strategi untuk mengatasi kebangkitan China ini. Pada tulisan ini, penulis akan menjelaskan strategi containment Amerika Serikat terhadap China dengan alasan untuk menjaga hegemoni Amerika Serikat dan tidak membiarkan China menjadi kekuatan baru yang akan mengancam keamanan dunia. Tulisan ini akan dibagi menjadi empat bagian, bagian pertama, penulis akan menjelaskan pengertian containment dan penggunaannya oleh Amerika Serikat di era Perang Dingin. Di bagian pertama juga, penulis akan menjelaskan hubungan Amerika Serikat dan China setelah Perang Dingin berakhir. Kemudian pada bagian kedua, penulis akan menunjukkan hubungan-hubungan yang dibentuk oleh Amerika Serikat dengan negara-negara lain yang memiliki lokasi geografis di sekitar China untuk memastikan strategi containment yang diterapkan oleh Amerika Serikat terhadap China berhasil. Sementara pada bagian ketiga, penulis akan menjelaskan containment dengan menggunakan landasan teori offensive realism yang dipostulasikan oleh John Mearsheimer. Penulis akan mengakhiri tulisan ini dengan kesimpulan di bagian keempat. 


\section{Posisi China dalam Kebijakan Global Amerika Serikat Pasca Perang Dingin}

Peningkatan pengaruh China semakin tidak terelakkan dan ini merupakan kondisi yang harus diterima oleh Amerika Serikat. Selain mempunyai ambisi yang sangat besar, Cina juga didukung oleh kekuatan ekonomi sehingga upaya strategi rebalancing Amerika Serikat semakin sulit. Kesulitan tersebut antara lain juga terlihat dari kompleksnya permasalahan China dengan Taiwan, nuklir Korea Utara, permasalahan teritorial maritim Laut China Selatan, yang tentunya berdasar aspek-aspek tersebut berimplikasi pada kehadiran militer AS di kawasan Asia Pasifik (Syahrin 2018). Mearsheimer (2006) beranggapan bahwa, China akan cenderung mendominasi belahan bumi Asia seperti Amerika Serikat yang mendominasi belahan bumi Barat. Secara spesifik, China akan memaksimalkan kekuatannya sehingga muncul gap kekuatan antara China dengan tetangganya terutama Jepang dan Rusia. China akan memastikan bahwa negaranya menjadi paling kuat di Asia sehingga tidak ada negara di Asia lain yang mampu mengancam China. Namun perlu ditegaskan juga, China tidak menggunakan kekuatan militernya untuk menjadi hegemon layaknya Amerika Serikat yang yang menjadi hegemon di belahan bumi barat.

Amerika Serikat melihat China tidak hanya sebagai pesaing kuat yang muncul secara umum dengan mengancam kekuatan Amerika Serikat sebagai aktor social control, tetapi juga sebagai ancaman politik dan ekonomi. Hal ini karena terdapat pertentangan antara China dan Amerika untuk dapat bekerja sama, terutama mengenai perbedaan nilai serta ideologi bahkan hingga kemunculan kekuatan China yang telah dianggap mengancam untuk menutup Asia Timur dari masuknya pengaruh ideologi dan ekonomi Amerika Serikat (Layne, 2008).

\section{Kerjasama-Kerjasama Amerika Serikat dengan Negara- Negara di Sekitar China sebagai Implikasi Containment Amerika Serikat terhadap China}

Pada saat Barack Obama masih menjabat menjadi presiden, Amerika Serikat mengambil langkah strategis terhadap China yaitu membuat US Pivot terhadap Asia Timur. Kebijakan tersebut memiliki karakteristik seperti kerjasama strategis secara luas dengan negaranegara Asia Timur, termasuk aliansi tradisional dan aliansi baru 
keamanan(Ross 2013). Bahkan negara-negara lain yang berada di sekitar China, seperti Jepang, Korea Selatan, Taiwan, bahkan India telah dilakukan penguatan kerjasama (Goldberg 2016). Menurut Hillary Clinton (2011), pivot yang dimaksud adalah salah satu tugas penting Amerika Serikat untuk mengunci peningkatan investasi yang penting dalam dekade mendatang. Esensi dari East Asia Pivot tersebut meliputi kerjasama bilateral dan kultural, yaitu dengan melakukan kerjasama secara langsung terhadap negara-negara sekitar China sehingga dapat mengunci perluasan pengaruh dari China secara geografis (Shambaugh 2013). Strategi East Asia Pivot pada masa Obama merefleksikan awal yang signifikan terhadap usaha Amerika Serikat untuk melakukan balancing terhadap bangkitnya China, pemerintahan Obama dalam usahanya juga telah memperluas hubungan dengan negara-negara daratan di pinggiran Cina - di Indocina dan di semenanjung Korea. Salah satu tujuan dari East Asia Pivot juga usaha untuk tetap membuat kawasan Asia Timur 'terbagi-bagi' (Ross 2013). Kebijakan yang dilakukan Obama dianggap sama dengan kebijakan Perang Dingin Amerika Serikat ketika Washington melakukan containment terhadap Uni Soviet mengenai paham komunisme dan liberalisme kala itu (Gardels 2018; Saetren 2018). Berbeda dengan sekarang yakni Amerika mempertahan posisinya sebagai hegemon dari kebangkitan kekuatan baru atau China (Saetren 2018).

Negara utama yang menjadi aliansi terdekat Amerika Serikat di Asia Timur adalah Jepang. Menurut Hughes (2009), kerjasama antara Amerika Serikat dan Jepang bersifat mutualisme, terutama dalam hubungan mereka dengan kebangkitan China. Hal ini dikarenakan Jepang juga merasa bahwa pengaruh yang diberikan Jepang pada negara-negara khususnya kawasan Asia menjadi menurun dengan adanya kebangkitan China. Tidak hanya itu, China juga menjadi long-term threat yang berpotensi dapat mengancam kepentingan negara-negara kawasan Asia Timur khususnya Jepang (Huges 2009). Bahkan tidak heran jika Jepang lantas meningkatkan budget militer hingga 46\% secara aspek militer (Mastro 2015). Dibalik alasan yang melatarbelakangi itu semua, kerjasama antara Amerika Serikat dengan Jepang merupakan hal penting bagi Amerika Serikat. Hal ini dikarenakan Jepang memberikan teritori bagi angkatan militer Amerika Serikat untuk berada sangat dekat dengan daratan China (Mastro 2015). Dalam sejarahnya, Jepang dan China tidak cukup bersahabat terutama setelah penjajahan Jepang terhadap China pada Perang Dunia II. Hal ini lantas memudahkan Amerika Serikat untuk memanfaatkanJepang sebagaitempatpangkalan militer(Khoo 2014). 
Selain Jepang, Korea Selatan juga menjadi aliansi strategis Amerika Serikat di Asia Timur. Sebenarnya, Korea Selatan mengizinkan Amerika Serikat menurunkan angkatan militer di Semenanjung Korea bukan karena permasalahan dengan China, melainkan permasalahan dengan Korea Utara. Korea Selatan sendiri tidak memiliki masalah yang sangat besar dengan China, hanya saja seringnya China berpihak pada Korea Utara menjadi concern tersendiri bagi Korea Selatan (Whyte 2015). Namun secara umum, Korea Selatan menganggap bahwa China bukanlah musuh utama mereka di Asia Timur. Berdasar hal tersebut, Korea Selatan menempatkan diri di tengah-tengah dengan tidak mengesampingkan kedua belah pihak dalam melakukan kerjasama. Hal ini dapat terlihat dengan posisi Seoul yang mengizinkan China mempengaruhi mereka secara ekonomi, dan satu sisi lain Seoul juga tetap beraliansi militer dengan Amerika Serikat. Aliansi militer dengan Washington inilah yang dimanfaatkan secara strategis oleh Amerika Serikat dalam hal containment terhadap China (Moon et al. 2017).

Taiwan juga baru-baru ini menjadi pihak yang menarik bagi strategi pivot to Asia milik Obama. Administrasi Obama menunjukkan ketertarikan terhadap Taiwan dengan menjual perangkat militer seharga \$6,4 milyar, termasuk didalamnya helikopter, misil pertahanan dan kapal selam (Watanabe 2013). Terhitung mulai 2002 hingga 2016, belanja militer Taiwan dari Amerika Serikat mencapai $\$ 15$ milyar (Thrall et al. 2018). Belum lagi ditambah ketika Donald Trump menjadi presiden Amerika Serikat, penjualan senjata Trump kepada Taiwan tidak berhenti dan mulai membuat China khawatir akan kebijakan Trump (Associated Press, 2017). Penjualan senjata yang dilakukan Amerika Serikat menurut Thrall dan Dorminey (2018) merupakan langkah Amerika Serikat yang tidak kalah konfrontatif dengan tindakan yang dilakukan di Jepang dan Korea Selatan. Perbedaannya hanya Amerika Serikat mengganti angkatan bersenjata dengan suplai senjata, namun kedua cara yang dilakukan Amerika Serikat dapat dikatakan mampu membuat China merasa tidak aman (Thrall et al. 2018).

Negara-negara Asia yang terletak di sekitar China, mulai dari Asia Timur hingga Asia Barat juga menjadi sangat krusial bagi containment Amerika Serikat. Tujuan containment adalah agar China tidak leluasa bergerak dengan strategi kepungan yang dilancarkan Amerika Serikat. Oleh karena itu, rencana Amerika Serikat dalam membentuk barikade dari timur hingga barat harus dipenuhi dengan aliansi-aliansi strategis dengan negara-negara seperti Afghanistan. Nega- 
ra seperti Afghanistan ataupun negara-negara Asia Tengah dan Barat lainnya memiliki kemampuan untuk membantu Amerika Serikat contohnya dalam perlintasan pipa minyak. Dengan menguasai politik di negara-negara tersebut, jalan pipa minyak tidak hanya akan dikuasai oleh China, namun Amerika Serikat juga memiliki kemampuan untuk mendikte jalur pipa minyak. Sehingga, melihat China yang sedang tumbuh dan membutuhkan minyak yang sangat banyak, menguasai pipa minyak akan menahan laju pertumbuhan China (Fallon 2013).

\section{Containment Amerika Serikat dalam Perspektif Offensive Realism John J. Mearsheimer}

Menurut Mearsheimer, suatu negara tidak akan mungkin bisa menjadi hegemon di dunia secara keseluruhan. Hal ini terjadi karena negara hegemon sebesar apapun tidak akan mampu memproyeksikan kekuatan mereka untuk mengatasi jika terjadi hal-hal yang tidak diinginkan di belahan bumi lain yang jauh letaknya. Pilihan yang tepat bagisuatu negarayang ingin menjadi hegemon menurut Mearsheimer adalah dengan menjadi regional hegemon di regional-nya sendiri. Namun, di lain sisi, negara yang menjadi regional hegemon tersebut juga harus memastikan bahwa di regional-regional lain tidak ada negara yang menjadi regional hegemon (Mearsheimer 2006).

KasusdemikianjugaterjadidalamkontravensiantaraAmerikaSerikat dan China pasca Perang Dingin berakhir. Keinginan Amerika untuk menjadi hegemon pun telah ditunjukkan sejak pertama kali Washington memerdekakan diri dari Inggris. Menurut Mearsheimer, setelah bangsa Eropa pergi dari Amerika Serikat, Washington telah menjadi regional hegemon yang tidak ingin kekuatannya disamai oleh negara di belahan bumi manapun. Usaha Amerika Serikat untuk menghentikan tumbuhnya hegemon-hegemon lain seperti Kerajaan Jerman pada Perang Dunia I, Jerman dan Jepang pada Perang Dunia II, serta Uni Soviet pada Perang Dingin adalah bukti usaha Amerika menurut Mearsheimer (2006). Maka dari itu, Amerika Serikat tidak akan diam saja dengan kekuatan China yang semakin besar.

Mearsheimer juga meramalkan bahwa munculnya China sebagai kekuatan ekonomi di Asia tidak akan damai. China tentu akan meningkatkan kekuatan militernya bersamaan dengan perekonomian 
mereka yang terus meningkat (Mearsheimer 2014). Hal ini yang kemudian menjadi perhatian Amerika Serikat. Salah satu cara yang digunakan oleh Amerika Serikat agar China tidak muncul sendirian sebagai satu-satunya hegemon di dalam regional Asia adalah dengan memantik negara-negara lain di sekitar China seperti Jepang, Rusia, dan Taiwan untuk bisa menjadi big power yang mampu menyaingi China. Keberadaan para big power di seketar China ini yang nantinya akan membantu Amerika Serikat untuk membuat China sibuk dalam persaingan dengan para big power. Kerjasama-kerjasama bilateral maupun multilateral dengan negaranegara Asia seperti yang sudah dibahas di bab sebelumnya menjadi langkah yang harus dilakukan Amerika Serikat dalam mengcontain kebangkitan China sehingga China tidak akan mampu berkonsentrasi untuk menjadi negara hegemon, tapi hanya akan sibuk bersitegang dengan negara-negara disekitarnya.

\section{Ancaman China terhadap Amerika Serikat jika China menjadi regional hegemon di Asia}

Terdapat dua hal yang akan sangat memberatkan bagi Amerika Serikat jika China menjadi regional hegemon dan mengganggu supremasi Amerika Serikat. Pertama, negara-negara Asia akan melakukan bandwagoning terhadap China dan memilih meninggalkan Amerika Serikat. Menurut Mearsheimer (2006), kebangkitan China bisa berdampak besar terhadap negara-negara yang secara geografis terletak di sekitar China. Saat ini, bukti-bukti otentik telah terlihat dimana China telah banyak sekali mempengaruhi kebijakan negara-negara kecil di sekitar China, terutama akibat peningkatan ekonomi China yang sangat pesat (Moon et al. 2017).

Satu isu ekonomi yang membuat Korea Selatan -secara engganmendekatkan diri kepada China terjadi pada rentang tahun 2014 dan 2015 ketika Korea Selatan masuk menjadi anggota Asian Infrastructure Investment Bank (AIIB) yang dipimpin oleh China untuk mendukung terciptanya peningkatan infrastruktur di negara-negara Asia. Menurut Moon, et al. (2017), pada awalnya Korea Selatan tidak ingin membahayakan relasi mereka dengan Amerika Serikat namun ada beberapa alasan yang membuat Korea Selatan berbalik. Alasan pertama adalah karena Kerajaan Inggris bergabung tiga minggu sebelum deadline untuk berpartisipasi di AIIB, diikuti oleh Prancis dan Jerman, begitu pula pemerintah konservatif Australia yang mengubah pendirian mereka dari 'no participation' menjadi 'positive 
consideration of participation.' Masuknya negara-negara yang juga merupakan aliansi Amerika Serikat tersebut membuat Seoul berpikir ulang, dan akhirnya bergabung dengan AIIB (Moon et al. 2017).

Alasan kedua Seoul untuk melakukan bandwagoning dibelakang China dalam AIIB adalah national interest. Beberapa anggota dari ruling party di Seoul, Saenuri menyarankan agar pemerintahan Park membedakan antara politik dan ekonomi. Para anggota partai menginginkan Korea Selatan masuk AIIB untuk kepentingan Korea Selatan sendiri. Sejalan dengan anggota Saenuri, para pebisnis juga menentang Park. Mereka mengatakan bahwa saat ini kebutuhan infrastruktur di Asia sedang meningkat, pemerintah Korea Selatan sendiri tidak mampu mendanai para pebisnis untuk mengambil keuntungan dari peningkatan kebutuhan infrastruktur Asia, begitu pula Asian Development Bank yang dipimpin oleh Jepang dan World Bank yang dipimpin Amerika Serikat. Oleh karena itu, para pebisnis mendorong Park untuk berpartisipasi di dalam AIIB untuk kepentingan nasional negara.

Alasan ketiga adalah desakan media massa. Hankook Ilbo, salah satu media Korea Selatan mempersuasi pemerintahan Park untuk mengikuti AIIB pada 15 Maret 2015 dengan menuliskan bahwa:

The United Kingdom joined the AIIB. There is no reason for the South Korean government to delay its participation ... The $A I I B$ and THAAD are different. The government should not hesitate to join the AIIB any more if it sees economic benefits (Moon, et al., 2017).

Begitu juga dengan harian Korea Joongang Daily, sebuah media konservatif di Korea Selatan, yang menerbitkan pendapatnya pada tanggal 16 Maret 2015 yang menyatakan bahwa Asia terdiri dari 60 negara dengan 4,4 milyar penduduk, dengan dibuatnya AIIB di Asia, maka pasar konstruksi Asia diharapkan bisa menghasilkan hingga 5 trilyun dollar Amerika Serikat. Editorial Joongang Daily juga menegaskan secara lebih lanjut bahwa "our construction and engineering firms can enjoy this new market” (Moon et al. 2017).

Pendirian Korea Selatan berubah satu minggu sebelum deadline (Moon et al. 2017). Hal ini menunjukkan ketertarikan Korea Selatan untuk melakukan bandwagoning ekonomi terhadap China disamping beraliansi dengan Amerika Serikat. Korea Selatan yang berada di bawah bayang-bayang China tentu tidak bisa menolak dan ingin berada di samping China yang sedang mengalami peningkatan ekonomi agar turut mendapatkan keuntungan bagi negara mereka. 
Tidak hanya Korea Selatan, dampak peningkatan ekonomi China juga dirasakan oleh negara-negara ASEAN. Pada tahun 2004, Perdana Menteri Malaysia, Abdullah Badawi mengatakan bahwa "China is today a creator of prosperity of the highest order. Political and social linkages are bound to eventually follow suit. It is therefore important to use every opportunity and establish ties" (Economy 2005). Jika dilihat dari perspektif Asia Tenggara, pola perdagangan China sangat menguntungkan. Asia Tenggara secara keseluruhan, mendapatkan surplus perdagangan dengan China sebesar \$8 milyar per tahun, kebanyakan dari ekspor bahan baku dan mesin presisi (Economy 2005). Economy juga menambahkan yakni pada 2010 ketika China-ASEAN FTA dibuka, ekspor China ke ASEAN akan tumbuh hingga \$10,6 milyar atau 55\%, sementara eksor ASEAN ke China akan naik sebanyak 48\% atau sebanyak $\$ 13$ milyar. Total volume perdagangan antara China dan ASEAN akan mencapai 1.2 trilyun dollar Amerika Serikat.

Bagi negara-negara disekitar China, pertumbuhan ekonomi bukanlah suatu ancaman. Korea Selatan dan Asia Tenggara telah merasakan dampak positif dari melambungnya perekonomian China (Moon et al. 2017; Ravenhill 2006). Hal ini juga tentu saja dirasakan oleh negara-negara Asia lainnya, begitu juga bagi negara-negara di seluruh dunia. GDP China pada tahun 2014 mencapai \$9,47 triliun, atau sekitar 13\% dari total GDP dunia (de Grauwe et al. 2016). Menurut IMF, China menjadi kontributor terbesar kepada GDP global pada tahun 2014 hingga 2015, dengan berkontribusi sebanyak $24 \%$ kepada pertumbuhan ekonomi global. Tren pertumbuhan ekonomi China tersebut tentu memberikan dampak yang cukup signifikan bagi dunia, terutama Asia sebagai negara-negara yang secara geografis dekat dengan China. Alasan bahwa national interest akan terpenuhi jika negara berhubungan dekat dengan China, seperti yang dilakukan Korea Selatan dan negara-negara ASEAN, maka strategi bandwagoning terhadap China akan semakin menjamur di Asia. Hal ini akan menyulitkan langkah Amerika Serikat melakukan containment terhadap China. Amerika Serikat tentu akan mengalami hambatan yang sangat besar karena proyek containment mereka tidak akan berguna tanpa adanya bantuan dari negaranegara di sekitar China.

Mearsheimer (2006) juga telah meramalkan, bahwa dengan pertumbuhan ekonomi China, kekuatan militer mereka akan semakin besar. Jika China memiliki kekuatan militer yang cukup besar, negaranegara seperti Rusia dan Jepang akan menjadi negara-negara inferior 
bagi pasukan militer China. Hal ini akan menambah kesulitan bagi Amerika Serikat karena negara-negara akan beralih pada China untuk membentuk sebuah aliansi demi keamanan negara masingmasing (Mearsheimer 2014; Mearsheimer 2010). Maka ketika hal tersebut terjadi, usaha containment Amerika Serikat akan berakhir sekaligus juga China akan muncul sebagai hegemon baru di regional Asia yang akan menjadi musuh Amerika Serikat dalam balance of power.

Alasan kedua yang membuat Amerika Serikat khawatir akan kemungkinan China yang menjadi hegemon adalah China tentu akan mengusir Amerika Serikat dari Asia. Negara hegemon tentu hanya akan menginginkan negara-negara lemah saja berada disekitarnya, pernyataan Mearsheimer (2006) ini didukung oleh fenomena Amerika Serikat sebagai hegemon belahan dunia Barat yang hanya mengizinkan negara-negara lemah seperti Meksiko dan Kanada berkembang di sekitarnya. Fenomena serupa juga didukung kasus Cuban Missile Crisis tahun 1962 ketika Uni Soviet berusaha mendekati Amerika Serikat secara geografis dengan mengirimkan misil ke Kuba. Akibat mispersepsi yang diterima Amerika Serikat, Washington mengalami security dilemma dan menginginkan Uni Soviet untuk pergi jauh dari 'halaman belakang' Amerika Serikat (Jervis 2001). Menurut Mearsheimer, hal itu merupakan tragedy of great power politics, yang berarti negara hegemon akan selalu tidak aman jika ada hegemon lain berada disekitarnya (Mearsheimer 2001).

Ulah China yang dianggap oleh beberapa pakar ingin mengusir Amerika Serikat dari Asia saat ini dengan membuat zonal defense. Tujuannya adalah untuk membuat US Navy tidak mendekati pantai China dan tidak mengintervensi deployment angkatan laut China di Laut Kuning dan Laut China Selatan. Saai ini, China mengembangkan DF-21D, sebuah anti-ship balictic missile (ASBM) dengan kemampuan mentarget U.S. carriers dan surface vessel besar (Buszynski 2012). Dalam hal ini China bertindak meski dalam kondisi yang belum benar-benar menjadi negara hegemon, dan sebagai negara yang tumbuh kearah hegemon tersebut tentu China tidak ingin sumber daya alam di Asia dikuasai oleh hegemon regional lain. Seperti dijelaskan sebelumnya, salah satu tujuan Amerika Serikat di Asia adalah mengamankan sumber daya minyak untuk keperluan mereka sendiri ataupun untuk melemahkan China. Sedangkan, China sebagai negara yang sedang mengalami modernisasi pasti sangat membutuhkan minyak untuk memenuhi kebutuhan seluruh 
penduduknya. Saat ini, China merupakan pengonsumsi minyak kedua terbesar di dunia dengan jumlah 8 juta barrel per hari pada tahun 2010. Pada tahun 2015, konsumsi minyak China meningkat hingga 11 juta barrel per hari, dan diramalkan akan mencapai 16,5 juta barrel per hari pada tahun 2030 (Seaman 2010). Hal ini menurut Buszynski membuat China membutuhkan banyak sekali suplai minyak, baik dari dalam negeri sendiri ataupun impor dari negara-negara penghasil minyak. Selama ini, 66\% minyak China berasal dari Saudi Arabia dan Angola. China juga telah mengklaim Laut China Selatan, salah satunya untuk alasan pengeboran minyak (Buszynski 2012). Kebutuhan akan minyak juga membuka kemungkinan besar bahwa China akan mengusir Amerika Serikat dengan aliansialiansi yang dibentuk oleh China dengan negara-negara sekitarnya (Zhao 2008). Sebagaimana tragedy of great power politics menurut Mearsheimer, tidak akan mungkin dua negara hegemon akan saling berbagi termasuk juga dengan sumber daya minyak. Maka dalam hal ini, China dan Amerika Serikat akan bersaing satu sama lain. Jika China menjadi hegemon, China tentu saja akan mengusir Amerika Serikat dari Asia. Akibatnya, impor minyak Amerika Serikat sebagai negara konsumen minyak tertinggi akan terkendala. Hal ini akan menjadi satu masalah yang akan ditemui oleh Amerika Serikat jika China telah benar menjadi hegemon di Asia.

\section{Kesimpulan}

Pada dasarnya Containment merupakan sebuah strategi pembendung yang pernah dilakukan oleh Amerika sebelumnya dan tentu dengan inti tujuan yang sama. Containment yang dilakukan oleh Amerika Serikat terhadap China kali ini ditandai dengan kegencaran Washington dalam melakukan kerjasama-kerjasama dengan negara-negara yang memiliki lokasi geografis disekitar China. Kerja sama dengan Jepang, Korea Selatan, Australia, Taiwan, bahkan India dan negara-negara Asia Barat dan Tengah merupakan cara yang dilakukan oleh Washington untuk mengepung China. Tujuan dari "pengepungan" yang dilakukan Amerika Serikat adalah membendung agar China tidak bebas bergerak dan memberikan pengaruh terhadap negara-negara kecil di Asia. Selain itu, dengan melakukan aliansi, Amerika Serikat juga menginginkan agar negaranegara aliansi di Asia mampu menjadi ekstensi kekuatan Amerika Serikat dan bisa menjadi lawan China sebagai great power. Keinginan Washington tentu saja agar negara-negara aliansi mampu mengganggu China agar tidak fokus dalam mengejar tujuan utama mereka sebagai hegemon regional dan juga agar mampu menjadi 
aliansi alternatif bagi negara-negara kecil di Asia sehingga tidak hanya melakukan bandwagoning dengan China saja. Semua hal tersebut dilakukan guna mencegah China untuk menjadi hegemon Asia. Karena dengan menjadi hegemon, posisi Amerika sebagai negara hegemon akan terancam. Berdasar hal tersebut, dengan anggapan bahwa menghentikan China sebagai negara hegemon di Asia, maka Amerika Serikat tidak akan mendapat saingan dan bisa terus menjadi negara hegemon meskipun posisinya lebih dominan di belahan bumi barat. Memang bukan hal yang salah jika hanya pada bumi belahan barat, karena selayaknya yang Mearsheimer katakan bahwa tidak mungkin bagi negara hegemon untuk menjadi global hegemon, karena akan terlalu sulit memproyeksikan kekuatan mereka. Berdasar hal tersebut pula yang mendorong Amerika untuk tetap mengawasi atau bahkan membendung negara-negara yang mencoba untuk menyamai kekuatan Amerika dengan tujuan agar Amerika tetap pada posisinya sebagai negara hegemon satusatunya di dunia. 


\section{Daftar Pustaka}

\section{Buku}

Mearsheimer, J.J. The tragedy of great power politics [Book]. New York : Norton \& Company, 2001.

\section{Jurnal dan Jurnal Online}

Buszynski, Leszek The South China Sea: Oil, Maritime Claims, and U.S. China Strategic Rivalry [Journal]. The Washington Quarterly 35:2. 2012. Pp 139-156.

de Grauwe, Paul and Zhang Zhaoyong. The rise of China and regional integration in east Asia. [Journal]. Scottish Journal of Political Economy, 63 (1). 2016. Pp 1-6.

Delage, Fernando. THE ASIAN STRATEGY OF XI JINPING [Journal]. Journal of the Spanish Institute for Strategic Studies N. 5. 2015.

Economy, Elizabeth. China's Rise in Southeast Asia: implications for the United States [Journal] . Journal of Contemporary China 14(44). 2005. Pp 409-425.

Gibbs, David. Does the USSR Have a 'Grand Strategy'? Reinterpreting the Invasion of Afghanistan [Journal] . Journal of Peace Research. 1987. Pp 365-379.

Hartman, Andrew. 'The Red Template': US Policy in Soviet-Occupied Afghanistan [Journal] . Third World Quarterly. 2002. Pp 467489.

Herring, George C. America and Vietnam: The Unending War [Journal] . Foreign Affairs, Vol. 70, No. 5, America and the Pacific. 1991. Pp 104-119.

Herring, George C. The Cold War and Vietnam [Journal] . OAH Magazine of History, Vol. 18, No. 5, Vietnam. 2004. Pp 18-21.

Hughes, Christopher W. Japan's Response to China's Rise: Regional Engagement, Global Containment, Dangers of Collision [Journal] . International Affairs (Royal Institute of International Affairs 1944), Vol. 85, No.4. 2009. Pp 837-856. 
Ikenberry, John. Power and liberal order: America's postwar world order in transition [Journal] . International Relations of the Asia-Pacific Volume 5. 2005. Pp 133-152.

Jervis, Robert. Perception and Misperception in International Politics [Book]. New Jersey, NJ : Princeton University Press, 1976.

Jervis, Robert. Was the Cold War a Security Dilemma? [Journal]. Journal of Cold War Studies Vol. 3, No. 1. 2001. Pp 36-60.

Khoo, Nicholas. China's Policy toward Japan: Looking for a Great Power Peace in the Wrong Places [Journal] . Georgetown Journal of Asian Affairs. 2014. Pp 49-76.

Layne, Christopher. China's Challenge to US Hegemony [Journal] . Current History. 2008. Pp 13-18.

Mearsheimer, J. J. The Gathering Storm: China's Challenge to US Power in Asia [Journal]. The Chinese Journal of International Politics, Vol. 3. 2010. Pp 381-396.

Mearsheimer, John J. China's Unpeaceful Rise [Journal] . Current History. - 2006. - pp. 160-162.

Moon, Chung-In and Boo Seung-chan. Coping with China's rise: Domestic politics and strategic adjustment in South Korea [Journal] . Asian Journal of Comparative Politics Vol 2(1). 2017. Pp 3-23.

Powers, Richard J. Containment: From Greece to Vietnam, and Back? [Journal] . The Western Political Quarterly, Vol. 22, No. 4 . 1969. Pp 846-861.

Ravenhill, John. Is China an Economic Threat to Southeast Asia? [Journal] . Asian Survey, Vol. 46, No. 5. 2006. Pp 653-674.

Roberts, Chalmers M. [et al.] How Containment Worked [Journal] . Foreign Policy, No. 7. 1972. Pp 41-53.

Ross, Robert S. US Grand Strategy, the Rise of China, and US National Security Strategy for East Asia [Journal]. Strategic Studies Quarterly, Vol. 7, No. 2, ASIA-PACIFIC SPECIAL EDITION. 2013. Pp 20-40.

Shambaugh, David. Assessing the US "Pivot" to Asia [Journal]. 
Strategic Studies Quarterly, Vol. 7, No. 2, ASIA-PACIFIC SPECIAL EDITION: Air University Press. 2013. Pp 10-19.

Syahrin, M. Najeri Al. Kompleksitas Keamanan Kawasan dan Tantangan Kerja Sama Keamanan Asia Timur [Journal] . Nation State: Journal of International Studies. 2018. Pp 2343 .

Thrall, Trevor and Dorminey Caroline. The Role of Arms Sales in U.S. Foreign Policy [Journal] . PolicyAnalysis 836. 2018.

Watanabe, Tsuneo. US Engagement Policy toward China: Realism, Liberalism, and Pragmatism [Journal] . The Journal of Contemporary China Studies, Vol.2, No. 2. 2013. Pp 3-24.

Zhang, Baohui. Xi Jinping, 'Pragmatic' Offensive Realism and China's Rise [Journal] . Global Asia. - 2014. - 2 : Vol. 9. Pp 71-79.

Zhao, Suisheng. China's Global Search for Energy Security: cooperation and competition in Asia-Pacific [Journal]. Journal of Contemporary China 17:55. 2008. Pp 207-227.

\section{Artikel Online}

Associated Press. 2017. Trump risks angering China with $\$ 1.4 b n$ arms deal to Taiwan [Online]. https://www. theguardian. Com. World. 2017. jun. 29. donald-trump-arms-deal-taiwanchina [diakses 6 Februari 2019].

Clinton Hillary. 2011. America's Pacific Century [Online]. Foreign Policy. dalam: https://foreignpolicy.com.2011.10.11. americas-pacific-century [diakses 28 Februari 2019].

Fallon,JosephE.2013.U.S.Geopolitics:AfghanistanandtheContainment of China [Online]. dalam: https://smallwarsjournal. com.jrnl.art.us-geopolitics-afghanistan-and-the-containment-of-china [diakses 7 Februari 2019].

Gardels, Nathan. 2018. Aiming to contain China would be a historic blunder [Online]. dalam: https://www. washingtonpost. com.news.theworldpost.wp.2018.11.16.us-china4.?noredirect $=$ on\&utm_term $=.0 c 65$ b9ddc6fd [diakses 5 Februari 2019]. 
Goldberg, Jeffrey. 2016. The Obama Doctrine [Online]. dalam: https://www. theatlantic. com. magazine.archive.2016.04. the-obama-doctrine.471525. [diakses 5 Februari 2019].

Mearsheimer, John. 2014. Can China Rise Peacefully? [Online]. dalam: https://nationalinterest. org.commentary.can-chinarise-peacefully-10204 [diakses 10 Februari 2019].

Saetren, Will. 2018. US cold war containment strategy against China may not end the Soviet way. Instead, it could explode into armed conflict [Online]. dalam: https://www. scmp.com.comment.insight-opinion.united-states.article. 2164221. us-cold-war-containment-strategy-against-china [diakses 5 Februari 2019].

Walker, Tony. 2018. As tensions ratchet up between China and the US, Australia risks being caught in the crossfire [Online]. dalam: http://theconversation.com.as-tensions-ratchet-upbetween-china-and-the-us-australia-risks-being-caught-inthe-crossfire-107178 [diakses 6 Februari 2019].

Whyte, Leon. 2015. The Evolution of the U.S-South Korea Alliance [Online]. dalam: https://thediplomat.com.2015.06.theevolution-of-the-u-s-south-korea-alliance. [diakses 5 Februari 2019].

\section{Lain-lain}

Seaman, John. Energy Security, Transnational Pipelines and China's Role in Asia [Report]. - Paris : Ifri Centre Asie, 2010. 